\title{
Computer simulation of railway wagon brake disc casting
}

\author{
Peter Futáśs ${ }^{1}$, Alena Pribulovál, Gabriel Fedorko², Vieroslav Molnár ${ }^{3}$ and Nikoleta Mikušová2 \\ ${ }^{1}$ Technical University of Kosice, Department of Metallurgy, Park Komenského 14, 04001 Košice, Slovakia \\ ${ }^{2}$ Technical University of Košice, F BERG, Logistics Department, Park Komenského 14, 04001 Košice, Slovakia \\ ${ }^{3}$ Technical University of Košice, FVT, Department of Computer Aided Manufacturing Technologies, Bayerova 1, 08001 Prešov, \\ Slovakia
}

\begin{abstract}
CAD systems serving as the model for real industrial processes are almost an inseparable part of manufacturing in many industry branches. The use of simulation programs in the foundry industry is perceived as a tool for the visualization of the processes involved in the production of castings. They are also used to resolve possible issues and imperfections before the production begins. Consequently, it enhances the quality and reduces product-manufacturing-related financial costs. The paper tackles the issue of how to resolve the occurrence of defects - shrinkages in the railway wagon disc casting while using a simulation program. The 3D model of the casting and of the system of gates was constructed in the CATIA CAD system. The mere simulation of the casting and solidification process was done in the NovaFlow\&Solid program. After evaluating the results of the simulation, the correction of the casting and gates was made in order at once to enhance the quality of the casting and reduce the production costs in the manufacturing of this casting. In the production of the brake disk casting, the main issues are little usage of molten metal during casting and the considerable occurrence of shrinkages, which causes the increased economic costs of its production.
\end{abstract}

\section{Introduction}

The simulation programs and simulations performed in them are currently common in the foundry and other industrial enterprises. They have a wide scope of usage since during the development of a particular product or process computer simulations can demonstrate a very detailed course of component production or of a process that is not actually observable under real conditions. It allows designers to look into the ongoing processes, to identify with high precision deficiencies and errors that could occur in the real production, and to modify them to ensure quality enhancement and the reliability of simulated processes.

Rail transport plays an important role in different types of logistics systems and in a wide range of industrial branches. Its operation is closely linked to high demands on safety and reliability. In order to meet the requirements, more attention needs to be paid not only to the operation of individual components and equipment but also to their actual manufacturing. The most important elements that are subjected to extreme stress during operation are railway wagon brake discs. They are a key factor in ensuring safe operation and are produced using gravity casting technology. One of the main factors for the proper functioning of a brake disc is the quality of the original blank casting.

The resultant quality of the casting is influenced by many factors and foundry principles, such as nondirectional solidification, risering, and cooling. Another important accompanying phenomenon is the shrinkage of the alloy during the casting process. This starts when the cast alloy is in the liquid state and lasts till the ambient temperature is reached. The reduction or change in volume that occurs in the liquid state is called shrinking, a distinctive foundry property of the material [1], [2]. The changes in the casting volume during the solidification process, resulting in the creation of shrinkages, are a natural phenomenon that cannot be avoided. Shrinking is a phenomenon that involves the reduction of the casting size during the transition from the liquid to the solid state. This phenomenon also causes that cavity shrinkage and casting porosity occurs. [3].

Therefore, it is important that the coarser and more massive parts of the casting rise upwards so that the coarser parts could be equipped with risers that would more easily ensure directional solidification [4], [5], [6].

\section{Modeling and simulation of casting}

In the production of high-quality castings, it is now necessary to use modern computer systems that can evaluate all the influences affecting the quality of the casting produced before its introduction into production.

Using computer simulation, we can find out how the mold cavity will fill and how the molten metal will solidify. From the filling and solidification simulation results, we can evaluate whether the system of gates and risers provides for directional solidification and also

\footnotetext{
* Corresponding author: gabriel.fedorko@tuke.sk
} 
whether it ensures the production of a defect-free casting. With computer simulation, it is easy to change the system of gates and risers without the need to produce a new one. Simulation also allows us to detect thermal stresses in castings [7].

Try to ensure that lines are no thinner than 0.25 point.

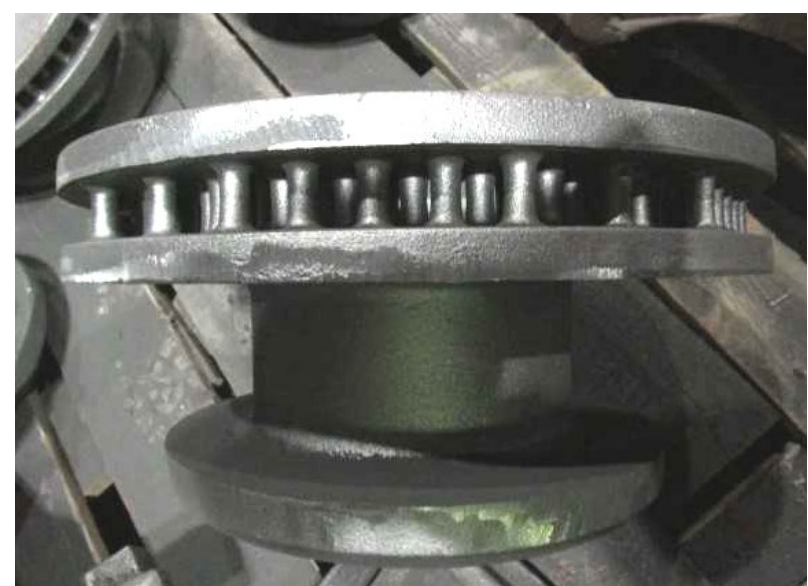

Fig. 1. Casting of the railway wagon brake disk.

The use of computer simulation facilitates rapid resolution of technological problems already in the prefabrication phase of the casting process, methodical elimination of technological errors, shortening of the preparatory time, and reduction of production costs.

To create a 3D model of a railway wagon brake disc casting (Fig. 1) as well as that of the system of gates and risers, CATIA V5R20 program was used (Fig. 2).
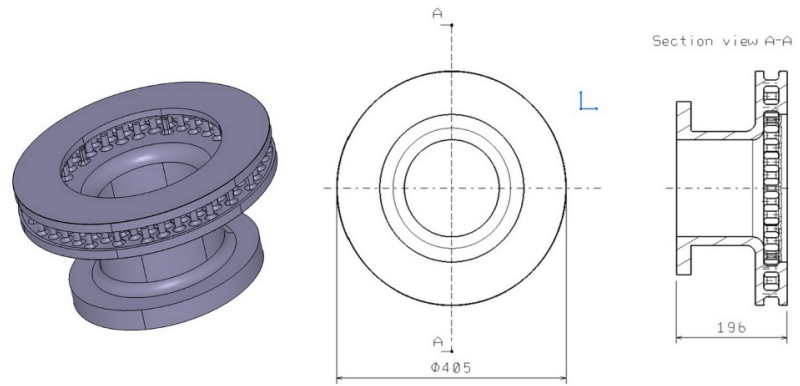

Fig. 2. 3D model of brake disc.

Fig. 3 shows a complete assembly of molded casting and a gate system with a single gate.

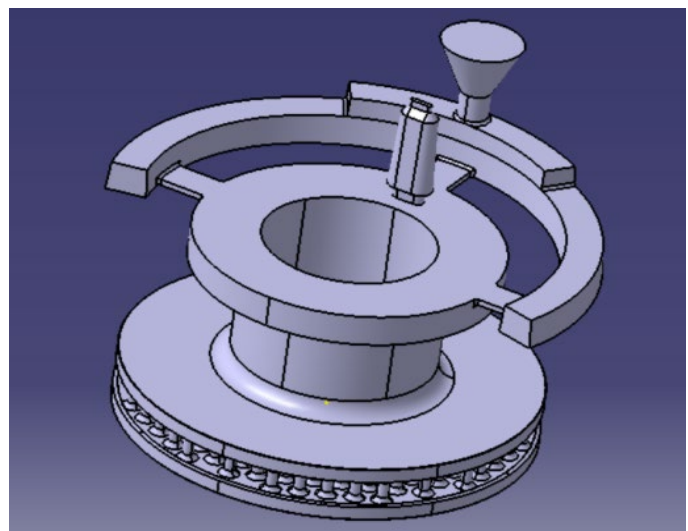

Fig. 3. 3D model of brake disc with a gate system.
The created assembly of the casting and the gate system was subjected to the computer simulation of casting and solidification processes using the NovaFlow \& Solid program. This simulation program from Novacast, Sweden, is being used, thanks to its simplicity and speed, to determine the course of filling and solidification of the molten metal in the foundry form, to find out where the foundry defects such as shrinkages and porosity can occur. This program is based on the Control Volume Method, which ensures accurate and fast creation of the simulation network. When creating a simulation network, the basic rule is that at least two cells need to be present in the narrowest cross-section. The finer a simulation network is, the more precise mere simulation is; however, the time needed to carry out the simulation is prolonged. In Fig. 4 is a close-up of a brake disk simulation network.

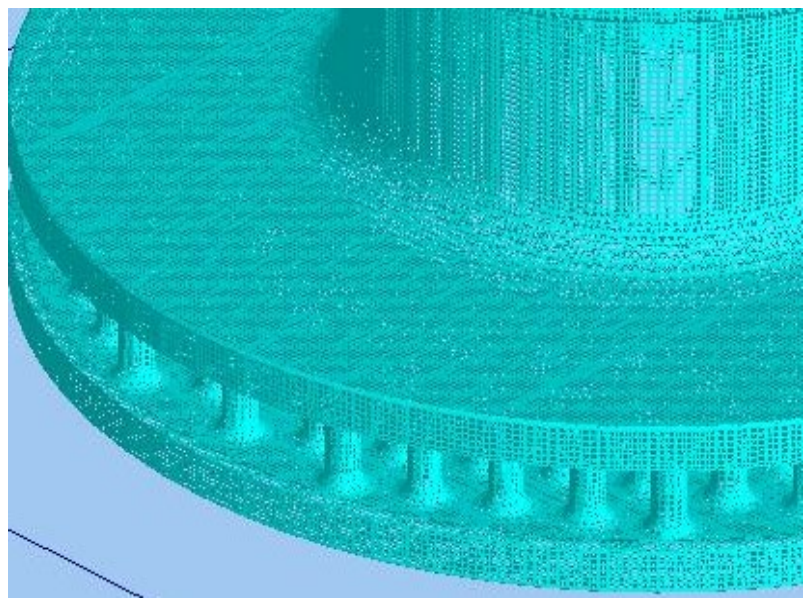

Fig. 4. A close-up of brake disk simulation network.

The input values that were used to simulate casting and solidification processes are given in Table 1 .

Table 1. Input values to simulate casting and solidification processes.

\begin{tabular}{|c|c|}
\hline $\begin{array}{l}\text { Casting } \\
\text { material }\end{array}$ & $\begin{array}{c}\text { EN-GJS-500- } \\
7\end{array}$ \\
\hline $\begin{array}{c}\text { Mold } \\
\text { material }\end{array}$ & Silica sand \\
\hline $\begin{array}{c}\text { Casting } \\
\text { process } \\
\text { temperature } \\
{\left[{ }^{\circ} \mathrm{C}\right]} \\
\end{array}$ & 1390 \\
\hline $\begin{array}{c}\text { Mold } \\
\text { temperature } \\
{\left[{ }^{\circ} \mathrm{C}\right]}\end{array}$ & 25 \\
\hline $\begin{array}{c}\text { Air } \\
\text { temperature } \\
\text { in the mold }\end{array}$ & 25 \\
\hline $\begin{array}{l}\text { Filling rate } \\
{\left[\mathrm{kg} \cdot \mathrm{s}^{-1}\right]}\end{array}$ & 0.5 \\
\hline $\begin{array}{c}\text { Moisture of } \\
\text { sand mixture } \\
{[\%]}\end{array}$ & 3 \\
\hline
\end{tabular}




\section{Analysis of casting and solidification simulation results}

Fig. 5 shows the fill rate at $20 \%, 40 \%$, and $95 \%$.
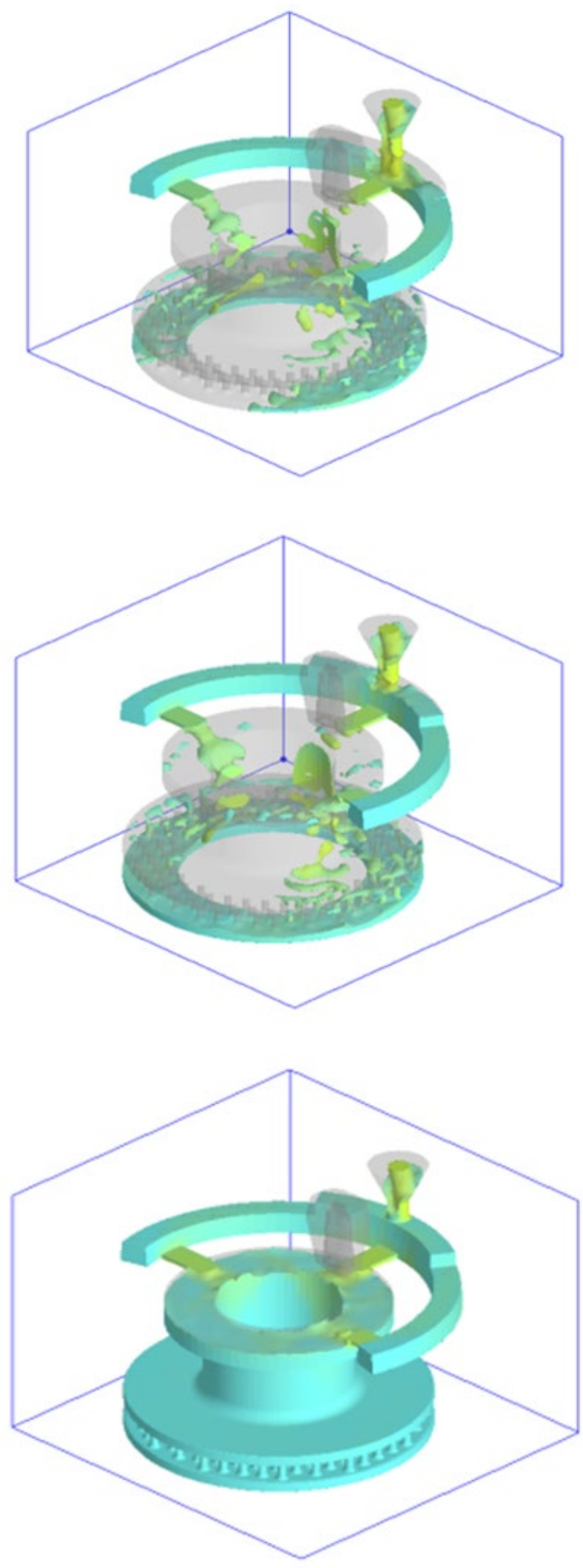

Fig. 5. The course of filling simulation.
From the filling simulation, it can be stated that the filling was running smoothly without spraying, which is a positive factor in filling the mold cavity. After the lower part of the casting was filled, the casting began to solidify from the distant places towards the gate system. The solidification process is shown in Fig. 6. Figures show the course of solidification at 5\%,20\%,40\%, and $80 \%$ moltenness. The casting solidifies as the last one and the shrinkage present does not interfere with the casting, but is formed in the riser, Fig.7. In case the shrinkage interferes with the casting, it would be necessary to adjust the size of the riser to eliminate it.
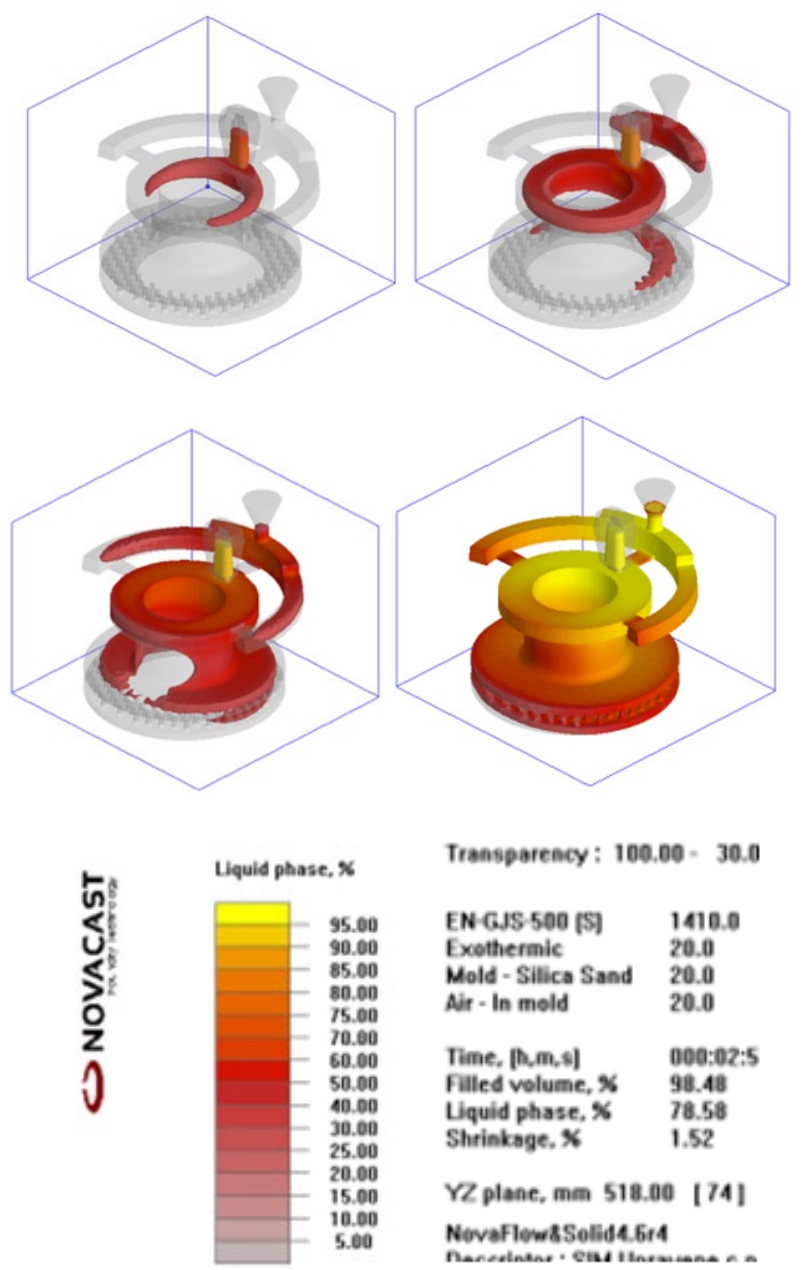

Transparency: $100.00-30.0$

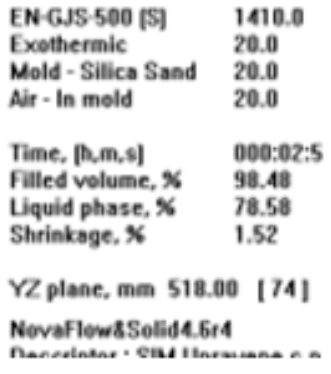

Fig. 6. The course of the simulation process.

\section{Conclusion}

The computer simulation of foundry processes brings countless benefits to casting production, and consequently cost savings when introducing a new type of casting into production. It offers the possibility of verifying the proposed gate system and the technology of the casting construction and its suitability for the casting process.

As the simulation of the casting and solidification of the railway wagon brake disc casting shows, the designed gate and riser system is sufficient and the casting solidified without adverse shrinkages and pores 
that would interfere with the casting. Also filling the mold cavity was smooth and would not cause erosion of the mold in the casting process.

The results obtained served to actually produce the casting and coincided with the results obtained in computer simulation.
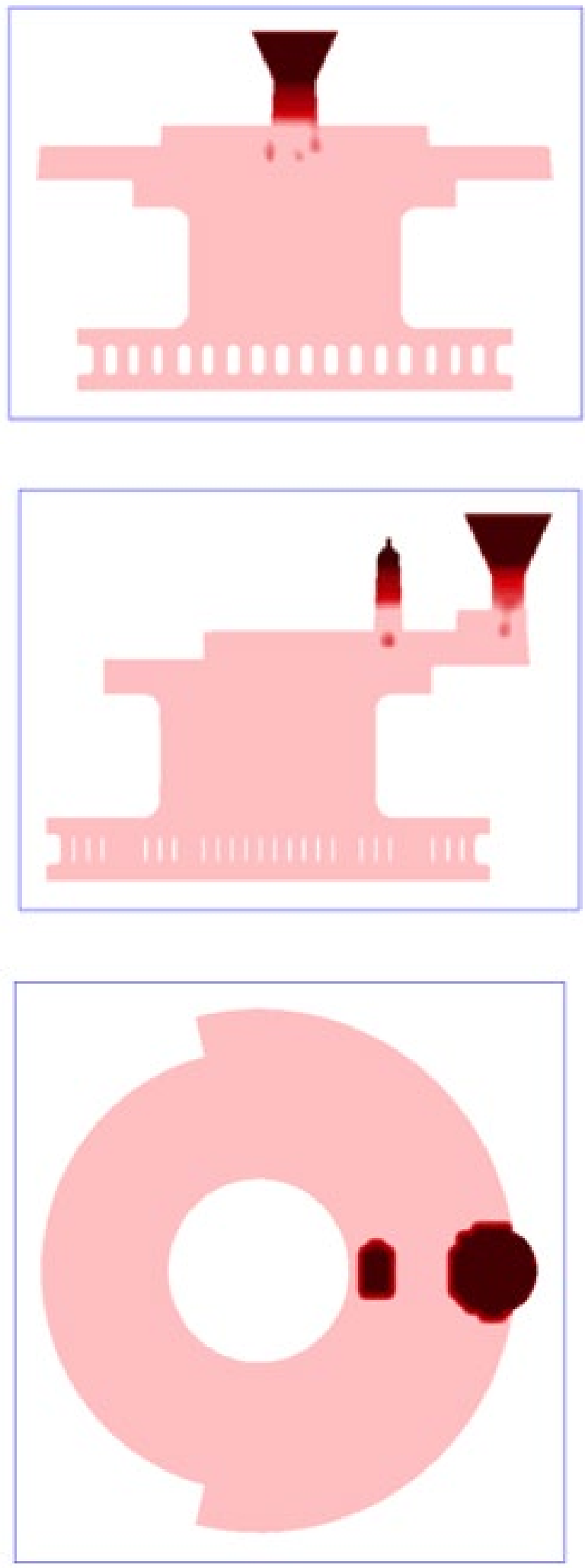

Fig. 7a. 3D model of brake disc with a gate system.

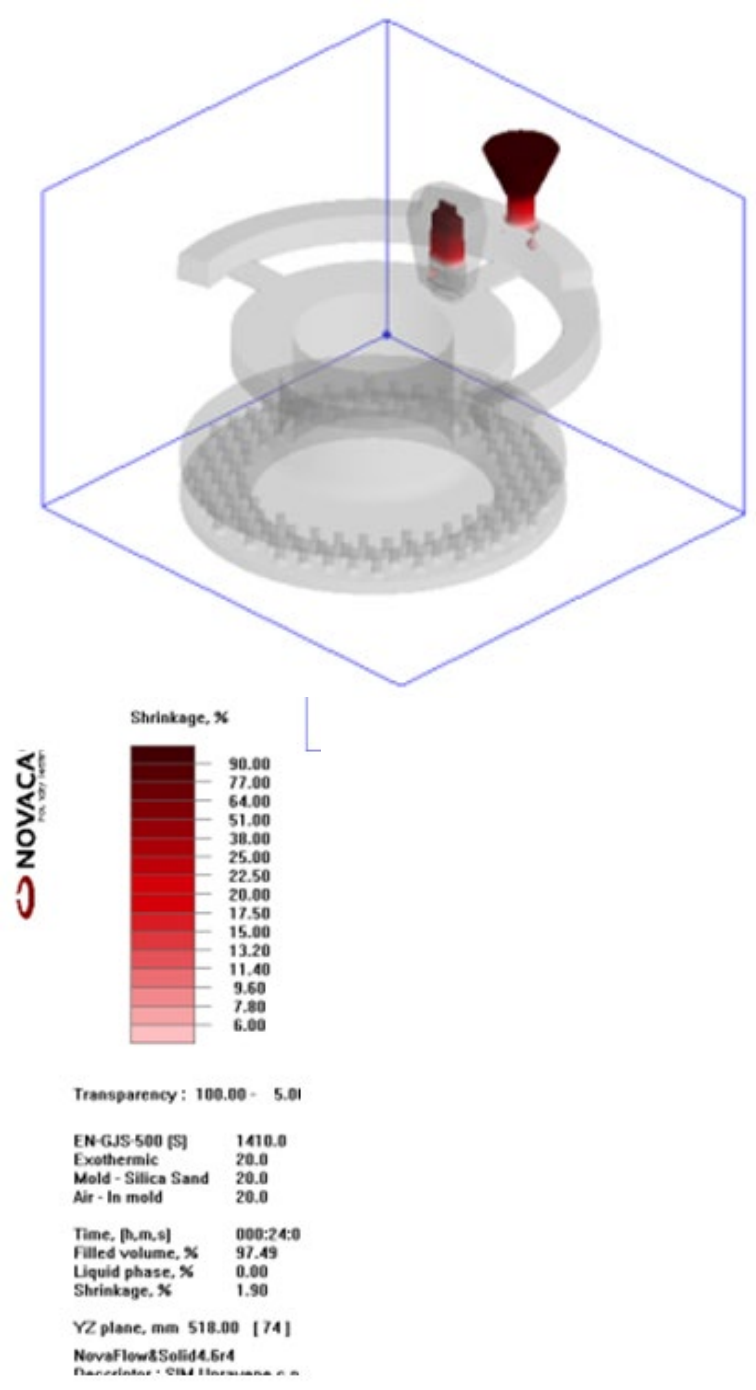

Fig. 7b. 3D model of brake disc with a gate system.

The present research is part of the following research grant projects: VEGA 1/0073/17, VEGA 1/0063/16, VEGA 1/0403/18, VEGA 1/059/19, KEGA 018TUKE-4/2016.

\section{References}

1. M. Holtzer, R. Danko, M. Gorny, Int. J. Cast.Wat. 29, 9 (2016)

2. C. Labrecque, M. Gagne, Can. M. Q. 5, 36 (1998)

3. C. Yeung, H. Zhao, W. Lee, Mat. Char. 40, 8 (1998)

4. T. Skrzypczak, W. Węgrzyn-Skrzypczak, Arch. Found. Eng. 10, 6 (2010)

5. K.M. Pedersen, N. Tiedje, Meas. 41, 10 (2008)

6. P.K. Basuktar, C.R. Loper Jr., C.L. Babu, AFS. Trans. 78, 8 (1970)

7. P. Futas, J. Imrich, I. Vaskova., G. Fedorko, V. Molnar, P. Kacmary, J. Sc. R. Prod. 2, 6 (2013) 